\title{
Comparative assessment of therapeutic efficacy of topical luliconazale versus topical ketoconazole in the treatment of pityriasis versicolor
}

\author{
Ellabanthini Hima Bindu
}

Assistant Professor, Department of Pharmacology, Osmania Medical College, INDIA. Email: drhimabindu54@gmail.com

Abstract Background: Pityriasis versicolor is a mild, persistent, typically asymptomatic fungal stratum corneum infection caused by Malassezia yeasts. Pityriasis versicolor is a common benign, superficial skin fungal infection, also known as tinea versicolor. It is a disease linked with Malassezia yeasts. Clinical features of Pityriasis versicolor show both hypo and hyper pigmented scaly macules. Objective: To compare the efficacy of topical luliconazole vs topical in ketoconazole in treatment of Pityriasis versicolor Design: Hospital based observational prospective analysis Duration: One year from January 2018 to December 2018 Setting: Dermatology outpatient department Participants: 100 patients Methods: A total of 100 patients with skin lesions of Pityriasis versicolor attending the Dermatology Outpatient Department. The patients were randomly divided into two groups Group A and Group B with each group containing 50 patients each. The first group i.e. Group A were treated with topical luliconazole $1 \%$ and the other group were treated with topical ketoconazole $2 \%$. Both groups were advised to apply twice daily for 4 weeks i.e. 28 days. Both clinical and mycological assessment was done to all the patients in both the groups initially and on two follow-ups one being in the $2^{\text {nd }}$ week i.e. 14 days and the other follow up in the $4^{\text {th }}$ week i.e. 28 days. Results: $1^{\text {st }}$ follow up after 2 weeks i.e. $14^{\text {th }}$ day $81 \%$ were negative in the treated luliconazole group and around $70 \%$ were negative in the treated ketoconazole group. On the $2^{\text {nd }}$ follow up after completion of $4^{\text {th }}$ week i.e. $28^{\text {th }}$ day $95 \%$ of the patients were negative in the treated luliconazole group while $74 \%$ of the patients treated with ketoconazole group were tested negative. Conclusion: Both topical luliconazole and topical ketoconazole were effective in treating pityriasis versicolor, But topical luliconazole has been found to be more effective than topical ketoconazole over a span of 4 weeks.

Key Word: Pityriasis versicolor, Luliconazole, Ketoconazole, Potassium Hydroxide -KOH

"Address for Correspondence:

Dr Ellabanthini Hima Bindu, Assistant Professor, Department of Pharmacology, Osmania Medical College, INDIA.

Email: drhimabindu54@gmail.com

Received Date: 20/11/2019 Revised Date: 19/12/2019 Accepted Date: 11/01/2020

DOI: https://doi.org/10.26611/10101311

\begin{tabular}{|l|l|}
\hline \multicolumn{2}{|c|}{ Access this article online } \\
\hline Quick Response Code: & Website: \\
\hline & www.medpulse.in \\
\cline { 2 - 2 } & \\
\hline
\end{tabular}

\begin{abstract}
INTRODUCTION
Pityriasis versicolor is a superficial chronically recurring, stratum corneal fungal infection characterized by scaly irregular dyspigmented macules most often found on the trunk and limbs. ${ }^{1,2,3 .}$ It is one of the world's most prevalent pigmentary skin disorders. It often occurs in teenagers and young adults, but is also seen in other age groups. It is similarly impacting men and women and there has not been a particular ethnic predominance. ${ }^{4,5}$ Pityriasis versicolor is usually diagnosed on the basis of its clinically presented hypo or hyper pigmented, scaled patches or plaques. ${ }^{6,7,8} \mathrm{It}$ does not result in either permanent scarring or pigmentation disorders. Nonetheless, following effective treatment, recurrence of disease can occur in many
\end{abstract}

How to cite this article: Ellabathini Hima Bindu. Comparative assessment of therapeutic efficacy of topical luliconazale versus topical ketoconazole in the treatment of pityriasis versicolor. MedPulse International Journal of Pharmacology. January 2020; 13(1): 01-04. https://www.medpulse.in/Pharmacology/ 
cases. ${ }^{9,10,11}$ A skin scrapping with $10 \% \mathrm{KOH}$ will detect the organism and it reveals small dense hyphae's with a large number of different sized spores ranging from spaghetti to meat-ball shapes. In treating pityriasis versicolor with an overall positive result there are many systematic and topic anti-fungal products of different form being used. Luliconazole, a member of the azole class, has good fungicidal activity, close to that of terbinafin against Trichophyton spp. Luliconazole is an antifungal medication that is new, optical effective and novel. ${ }^{12} \mathrm{~A}$ ketene dithioacetate formulation has been incorporated into the imidazole campaign to improve the specific chemical structure of luliconazole, and it has a strong inhibitory activity against filament fungi such as Dermatophytes and Malassezia organisms. Ketoconazole is a water soluble synthetic imidazole group of antifungal medicinal products with a wide range of anti-mycotic activity with a broad spectrum of activity against dermatophytes and yeast. Ketoconazole is used to combat serious fungal skin infections. ${ }^{13,14,15,16}$ The goal of the present study is to evaluate this therapeutically more effective drug in the treatment of Pityriasis versicolor with topical luliconazole $(1 \%)$ cream compared with topical ketoconazole $(2 \%)$.

\section{MATERIALS AND METHODS}

Place of Study: Outpatient Department of dermatology Type of Study: This was a hospital based observational study.

Sample Collection: Sample size : 100 patients.

Sampling Methods: Consecutive sampling

Inclusion Criteria: Patients with confirmed diagnosis of pityriasis versicolor with $10 \% \mathrm{KOH}$ mount

Exclusion Criteria: Patients with Pityriasis versicolor skin lesions who already received topical or systemic antifungal treatment and pregnant women

\section{OBSERVATIONS AND RESULTS}

Out of 100 patients, 86 patients were selected for this study. 60 Patients were male constituting $69.7 \%$ and the rest 26 were females constituting $30.3 \%$. The male to female ratio was $2.3: 1$ which shows male predominance.

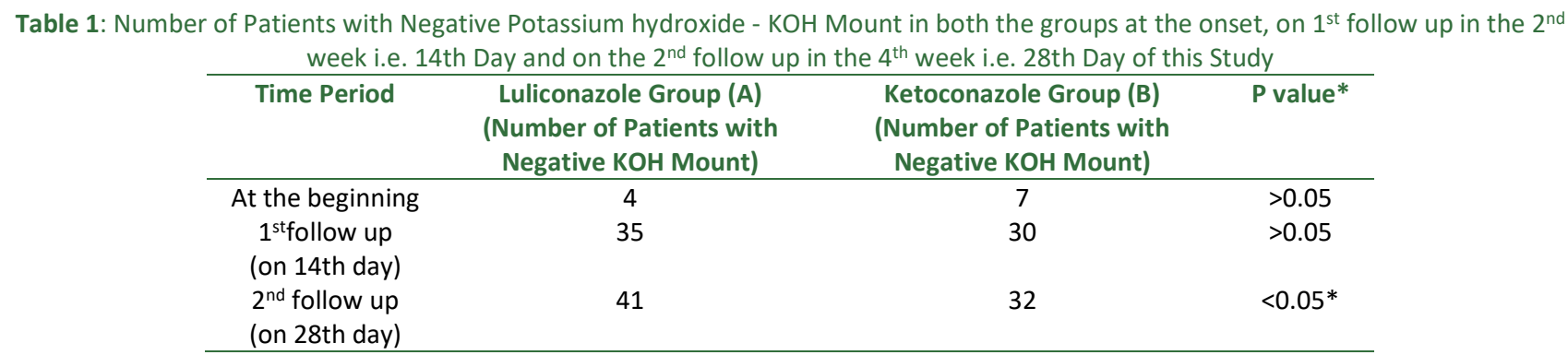

Statistical Analysis: Data were presented in the form of statistical Tables and charts. SPSS software version 20 was used for statistical analysis.

Ethical Approval: Approval was taken from the Institutional Ethics Committee prior to commencement of the study.

A total of 100 patients with skin lesions of Pityriasis versicolor attending the Dermatology Outpatient Department were taken. The patients were randomly divided into two groups Group A and Group B with each group containing 50 patients each. The first group i.e. Group A were treated with topical luliconazole $1 \%$ and the other group were treated with topical ketoconazole $2 \%$. Both groups were advised to apply twice daily for 4 weeks i.e. 28 days.

The diagnosis of Pityriasis versicolor is usually made based on clinical examination findings but both clinical and mycological assessment was done to all the patients in both the groups initially and on two follow-ups one being in the $2^{\text {nd }}$ week i.e. 14 days and the other follow up in the $4^{\text {th }}$ week i.e. 28 days. The mycological assessment was done by scraping of the skin from the edge of the lesion and scrapings were collected directly on to the slide. Potassium hydroxide $10 \%$ was added to the collected material and observed under the microscope. Upon 10\% potassium hydroxide $(\mathrm{KOH})$ mount examination it revealed, hyphae's which were growing into strands within clumps of keratinocytes. Thick-walled spores were spotted in grape like clumps. Individual spores and short stubby hyphae's were floating in the clear areas between clumps of keratinocytes. Many of the short hyphae's were dystrophic. It had resemblance of spaghetti and meatball. The $\mathrm{KOH}$ mount was observed and result classified as positive or negative for Malassezia fungi. 
Total of 14 patients didn't turn up for the follow up visits. At the first follow up 5 patients didn't attend and in the $2^{\text {nd }}$ follow up 9 patients didn't follow up and we excluded them from our study.

$1^{\text {st }}$ follow up after 2 weeks i.e. $14^{\text {th }}$ day $81 \%$ were negative in the treated luliconazole group and around $70 \%$ were negative in the treated ketoconazole group. On the $2^{\text {nd }}$ follow up after completion of $4^{\text {th }}$ week i.e. $28^{\text {th }}$ day $95 \%$ of the patients were negative in the treated luliconazole group while $74 \%$ of the patients treated with ketoconazole group were tested negative.

\section{DISCUSSION}

Pityriasis versicolor is a fungal disease from the category of superficial fungus. This fungus causes chronic and recurrence infection of the layer of the skin that is created by lipophilic yeast from Malassezia. Human to-human transmission is possible through direct contact. In our study male patients are affected more $(69.7 \%)$ than the female $(30.3 \%)$. The most common age group affected with pityriasis versicolor were the teenagers belonging to the age group of $10-30$ years. Almost $90 \%$ of patients were asymptomatic. Only $10 \%$ of the patients were concerned about the cosmetic or aesthetic changes seen with the occurrence of hypo or hyper pigmentation. Topical agents can effectively treat pityriasis versicolor. The first line of treatment for the pityriasis versicolor is topical medicines, In the event of serious, extreme, recalcitrant or chronic cases, oral therapy is seen as a second line of treatment. These antifungal agents include Ketoconazole and Luliconazole. In the beginning of our study by using $\mathrm{KOH}$ mount we found that around $9 \%$ of the patients belonging to luliconazole group were found to be negative and in the ketoconazole group $16 \%$ of the patients were negative. On the $1^{\text {st }}$ follow up after 2 weeks i.e. $14^{\text {th }}$ day $81 \%$ were negative in the treated luliconazole group and around $70 \%$ were negative in the treated ketoconazole group. On the $2^{\text {nd }}$ follow up after completion of $4^{\text {th }}$ week i.e. $28^{\text {th }}$ day $95 \%$ of the patients were negative in the treated luliconazole group while $74 \%$ of the patients treated with ketoconazole group were tested negative. During the follow-up tests of this research, mycological changes in versicolor lesions of Pityriasis were statistically significative among both treated groups. Previous studies by Savin RC et al. ${ }^{17}$, Balwada RP et al. ${ }^{18}$, Chopra V et al. ${ }^{19}$ and Nagpal $\mathrm{VB}^{20}$ showed $80-90 \%$ cure rate with ketoconazole treatment for pityriasis versicolor.

\section{CONCLUSIONS}

The treatment of pityriasis versicolor was effectively performed with both topical luliconazole as well as with topical ketoconazole, however topical luliconazole over period of 4 weeks was found to be more effective than topical ketoconazole. The two were nearly identical in contrast with the 2 weeks of topical treatment with both luliconazole and ketoconazole.

\section{REFERENCES}

1. Brandi N, Starace M, Alessandrini A, Piraccini BM. Tinea versicolor of the neck as side effect of topical steroids for alopecia areata. J Dermatolog Treat. 2019 Dec;30(8):757759.

2. Choi FD, Juhasz MLW, Atanaskova Mesinkovska N. Topical ketoconazole: a systematic review of current dermatological applications and future developments. J Dermatolog Treat. 2019 Dec;30(8):760-771

3. Diongue K, Kébé O, Faye MD, Samb D, Diallo MA, Ndiaye M, Seck MC, Badiane AS, Ranque S, Ndiaye D. MALDI-TOF MS identification of Malassezia species isolated from patients with pityriasis versicolor at the seafarers' medical service in Dakar, Senegal. J Mycol Med. 2018 Dec;28(4):590-593.

4. Alvarado Z, Pereira C. Fungal diseases in children and adolescents in a referral centre in Bogota, Colombia. Mycoses. 2018 Aug;61(8):543-548.

5. De Luca DA, Maianski Z, Averbukh M. A study of skin disease spectrum occurring in Angola phototype V-VI population in Luanda. Int. J. Dermatol. 2018 Jul;57(7):849-855.

6. Errichetti E, Stinco G. Dermoscopy in General Dermatology: A Practical Overview. Dermatol Ther (Heidelb). 2016 Dec;6(4):471-507.

7. Prohic A, Jovovic Sadikovic T, Krupalija-Fazlic M, Kuskunovic-Vlahovljak S. Malassezia species in healthy skin and in dermatological conditions. Int. J. Dermatol. 2016 May;55(5):494-504.

8. Rosen T. Mycological Considerations in the Topical Treatment of Superficial Fungal Infections. J Drugs Dermatol. 2016 Feb;15(2 Suppl):s49-55.

9. Gupta AK, Foley KA. Antifungal Treatment for Pityriasis Versicolor. J Fungi (Basel). 2015 Mar 12;1(1):13-29.

10. Gupta AK, Lyons DC. Pityriasis versicolor: an update on pharmacological treatment options. Expert Opin Pharmacother. 2014 Aug;15(12):1707-13

11. Hawkins DM, Smidt AC. Superficial fungal infections in children. Pediatr. Clin. North Am. 2014 Apr;61(2):44355.

12. Niwano Y, Kuzuhara N, Kodama H, Yoshida M, Miyazaki T, Yamaguchi H Antimicrob Agents Chemother. 1998 Apr; 42(4):967-70.

13. Savin RC, Horwitz SN. Double-blind comparison of $2 \%$ ketoconazole cream and placebo in the treatment of pityriasis versicolor. J Am Acad Dermatol. 1986;15:500 3.

14. 8. Balwada RP, Jain VK, Dayal S. A doubleblind comparison of $2 \%$ ketoconazole and $1 \%$ clotrimazole in the treatment of pityriasis versicolor. Indian J Dermatol Venereol Leprol. 1996;62:298-300.

15. 9. Chopra V, Jain VK. Comparative study of topical terbinafine and topical ketoconazole in pityriasis versicolor. Indian J Dermatol Venereol Leprol. 2000;66:299-300.

16. 10. Nagpal VB, Jain VK, Aggarwal K. Comparative study of oral and topical ketoconazole therapy in pityriasis 
versicolor. Indian J Dermatol Venereol Leprol. 2003;69:287-8

17. Savin RC, Horwitz SN. Double-blind comparison of $2 \%$ ketoconazole cream and placebo in the treatment of tinea versicolor. J Am Acad Dermatol 1986;15(3):500-503.

18. Balwada RP, Jain VK, Dayal S. A double-blind comparison of $2 \%$ ketoconazole and $1 \%$ clotrimazole in the treatment of pityriasis versicolor. Indian J Dermatol Venereol Leprol 1996;62(5):298-300.
19. Chopra V, Jain VK. Comparative study of topical terbinafine and topical ketoconazole in pityriasis versicolor. Indian J Dermatol Venereol Leprol 2000;66(6):299-300.

20. Nagpal VB, Jain VK, Aggarwal K. Comparative study of oral and topical ketoconazole therapy in pityriasis versicolor. Indian $\mathrm{J}$ Dermatol Venereol Leprol 2003;69(4):287-288.

Source of Support: None Declared Conflict of Interest: None Declared 